\title{
Extent of Armor Layer Development in the Sand- dominated San Antonio River
}

Chynna J. Spangle and J.K. Haschenburger The University of Texas at San Antonio, San Antonio TX, 78249

The surface and subsurface sediments were sampled
independently, as recommended by Kellerhals and Bray (1971). The independenlly, as reconmended by Kellerhals and Bray (1971). The samples of both the surface and subsurface were collected. The data collected in the field consisted of 72 bed material samples
obtained from 3 channel bars in spring of 2017 (fig. 3). To characterize whether armor layers were present, 12 paired surface and subsurface samples were collected from each bar head.

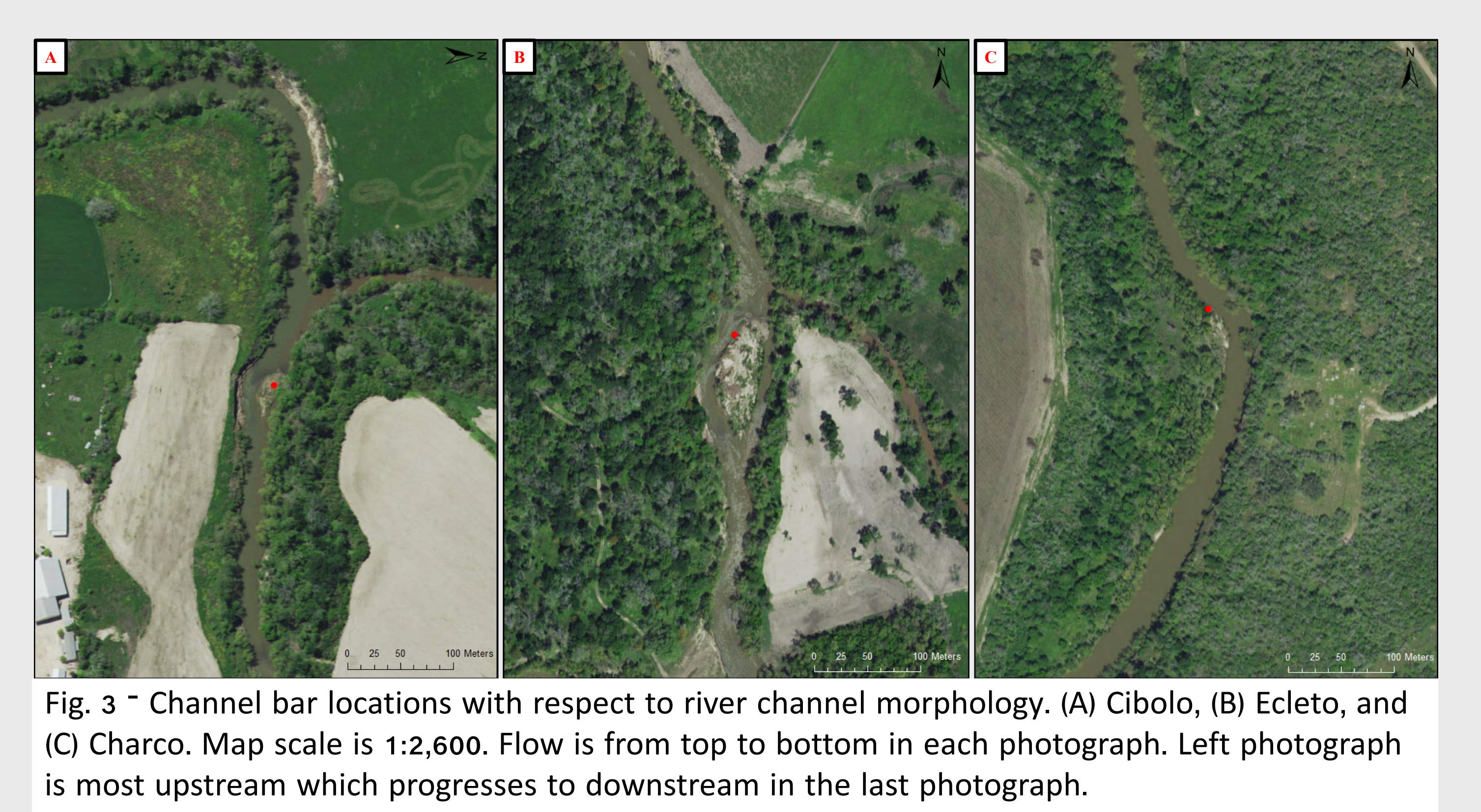

For each bar head, sample sites followed a $2 \times 3 \mathrm{~m}$ grid oriented $57 \times 57 \mathrm{~cm}$ area defined by a wooden frame whe surface sediment was removed to a $2-\mathrm{cm}$ depth and the immediate subsurfece samen was collected typically to a depth of $10 \mathrm{~cm}$. Characteristics of the bar sediment ranged from mud drapes to well exposed gravel up to 45 $\mathrm{mm}$ in size (fig. 4). Some a das were well covered by grasses.

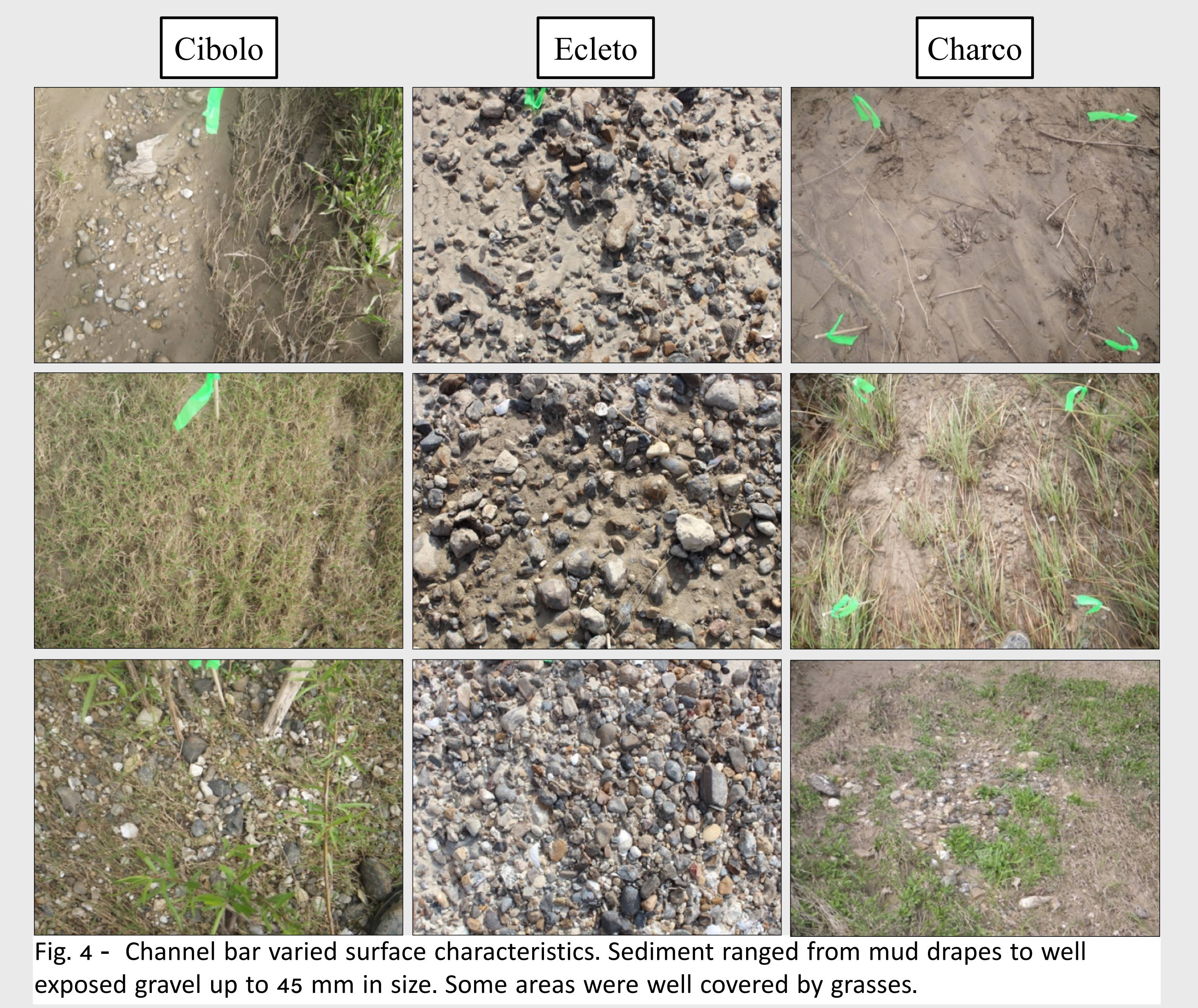

To characterize the amount of armoring, the ratio between $D_{50 \text { s }}$ and
$D_{500}$ was computed (Hassan et al. 2006), where $D_{50}$ is the surface $D_{50 b}$ was computed (Hassan et al. 2006), where $D_{50}$ is the surface
median diameter and $D_{500}$ is the subsurface median diameter. A lack of armor development is indicated by a ratio of 1 , whereas a welldeveloped armor will have a ratio of 2 or more (Hassan et al. 2006). Armor ratio values that are below 1 may indicate that fine sediment
covers the surface (Bunte et al. 2001).

\section{Results}

On the Cibolo bar the $D_{50 s}$ range from 0.15 to $16 \mathrm{~mm}$, whereas the $\mathrm{D}_{50 b}$ range from 0.15 to $4.8 \mathrm{~mm}$. Armor ratios average $9.8 \pm 2.9$, where $58 \%$ have a ratio of 2 or larger. Five significant outliers with ratio values of $16,16.4,20,23$, and 27 are found at positions 9,4 , 5,7 , and 6 , respectively (fig. 5 ).

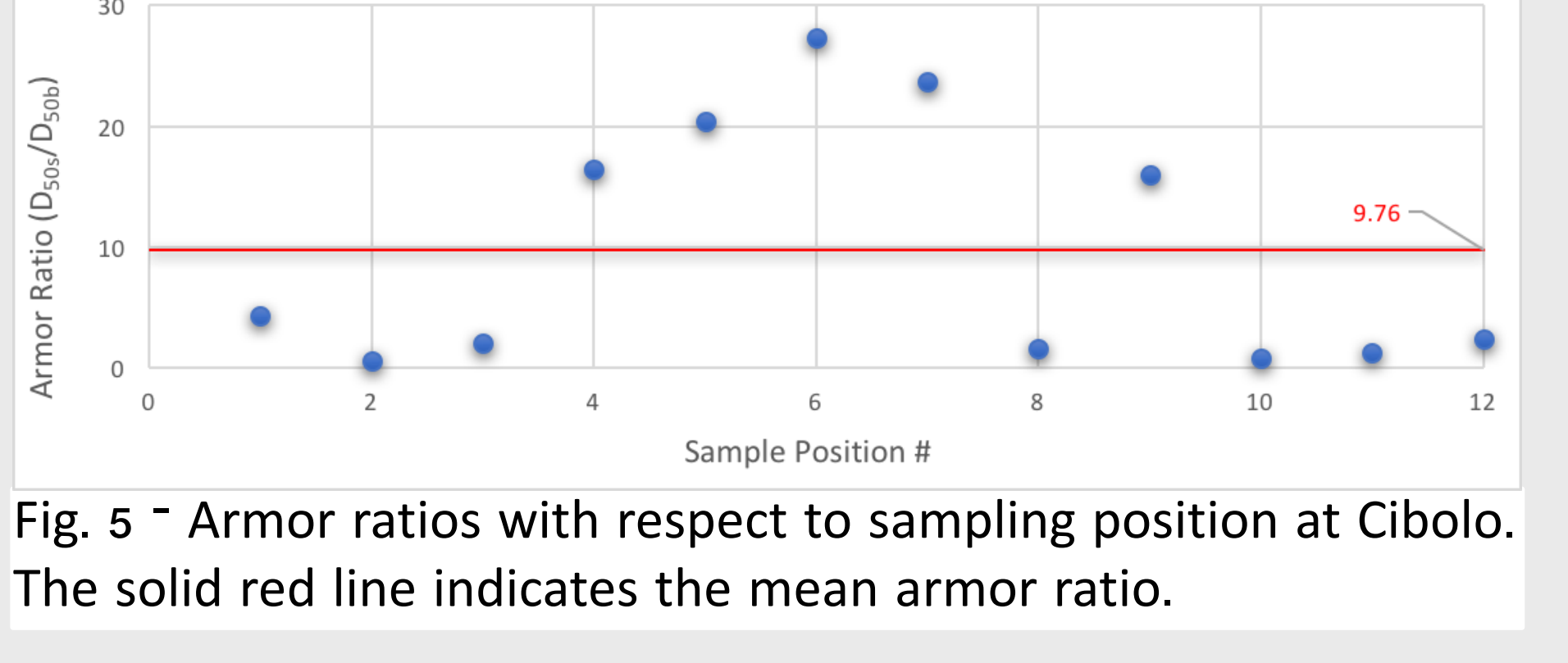

On the Ecleto bar $\mathrm{D}_{500}$ are more similar, ranging from 18.0 to 31.5 $\mathrm{mm}$ whereas the $D_{500}$ span a wider range of 0.77 to $13.3 \mathrm{~mm}$ Armor rallos average $8.6 \pm 3.3$, where $100 \%$ have a ratio of 2 or higher. Four significant outlers are at position $7,8,2$, and 3 with

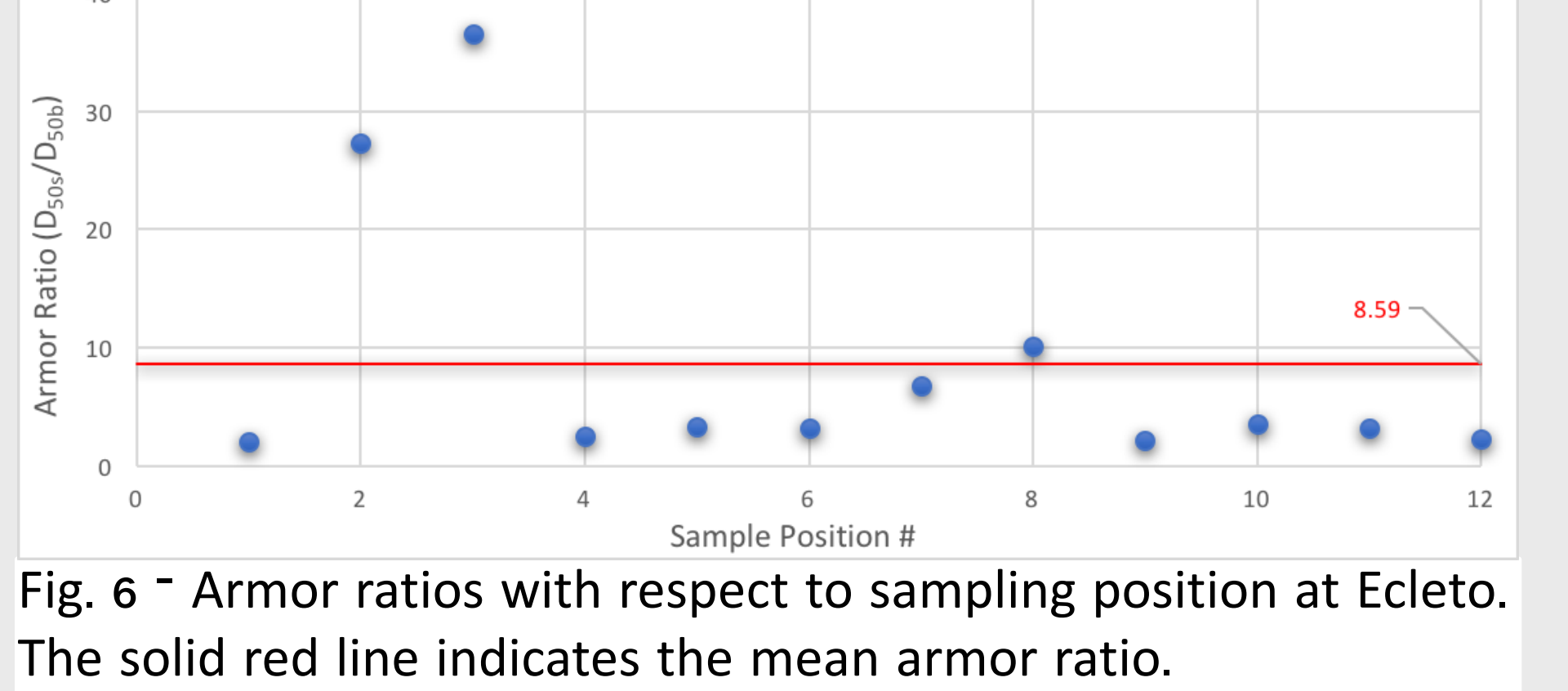

On the Charco bar $\mathrm{D}_{50 \mathrm{~s}}$ range from 0.12 to $12 \mathrm{~mm}$, whereas the $\mathrm{D}_{50}$ are more similar and range from 0.13 to $0.25 \mathrm{~mm}$. Armor ratios average $11.2 \pm 6.6$, where $25 \%$ have a ratio of 2 or higher. Three $7.7,53$, and 66 , respectively (fig. 7 ).

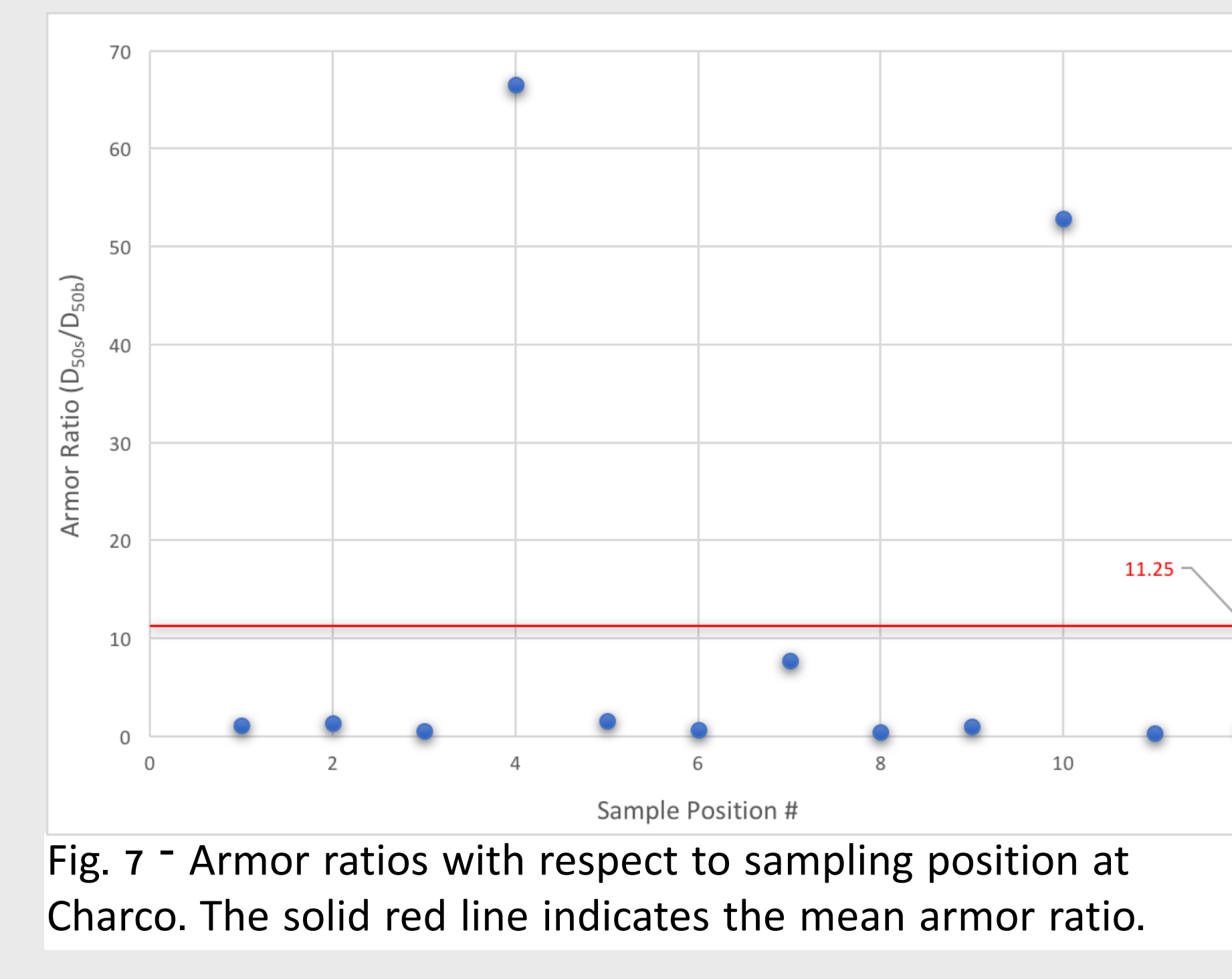

\section{Conclusions}

The main conclusions of this study are:

Armor layer development is documented on all three channel $25 \%$ to the maximum possible of $100 \%$. This sug from only local controls on sediment supply and transport are especially important in the process of armor development when gravel content in the bed material is low.

2) When armor is present, the armor ratios indicate that the Wo the the 20 times the thess of the characteristic size of subsurface sediment. This is best explained by the vertical segregation of sizes, gravel generally

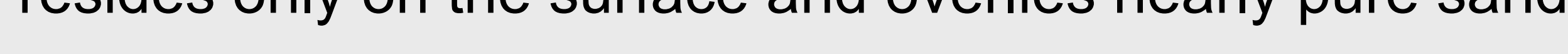

Further study is needed to improve understanding of armor layer development in poorly sorted sand-dominated rivers like the San

\section{References}

Buffington, J., and Montgomery, D. (1999). Effects of sediment supply on
surface textures of gravel-bed rivivers. Water Resour. Res., 35(11), 3523-
3530, doi:10.1029/1999WR900232. Bunte, K. . Abt. S. (2001). Sampling surface and subsurface particle-size
distributions in Wadable gravel- and cobble-bed streams for analyses in

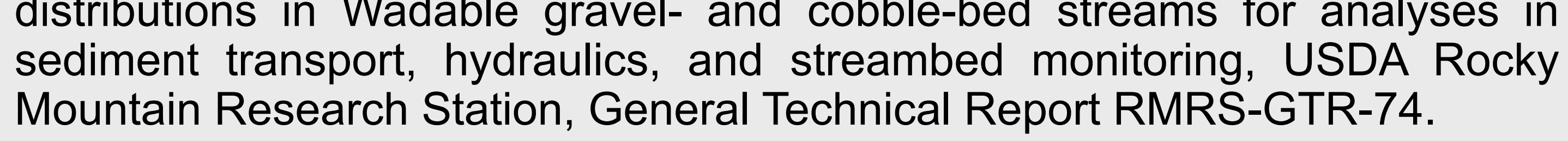
Church, M., and Haschenburger, J.K. (2017). What is the "active layer"? Water
Resour. Res., 52, doi:10.1002/2016WR019675. [Modified image.] Church, M., and Vendititi, J. (2014). Morphology and controls on the position of
a gravel-sand transititon: Fraser River, British Columbia, J. Geophys. Res.
Earth Surf., 119, 1959-1976, doi: 10.1002/2014JF003147. Dietrich, W.E., Kirchner, J.W. Ikeda, H., and Iseya, F. (1989). Sediment supply
and the evevelopment of the coarse surface layer in gravel-bedded rivers.
Nature, 340, 215-217, doi: $10.1038 / 34021500$. Hassan, M.A., Egozi, R, and Parker, G. (2006). Experiments on the effect of
hydrograph characteristics on vertical grain sorting in gravel bed rivers,
Water Kellerhals, R., and Bray, D. I. (1971). "Sampling procedures for coarse fluvial Melville, B.W., and Chin, C.O. (1986). "Stream Bed Armouring." gth Australasian Fluid Mechanics Conference. University of Auckland," New
Zealand. Parker, G., and Klingeman, P. (1982). On why gravel bed streams are paved.
Water Resour. Res., 18(5), 1409-1423, doi: 10.1029/NR018ii005p01409.

\section{Acknowledgements}

Fieldwork was supported by a grant from the San Antonio River
Authority awarded to JKH. Nick Castillo assisted with fieldwork. 